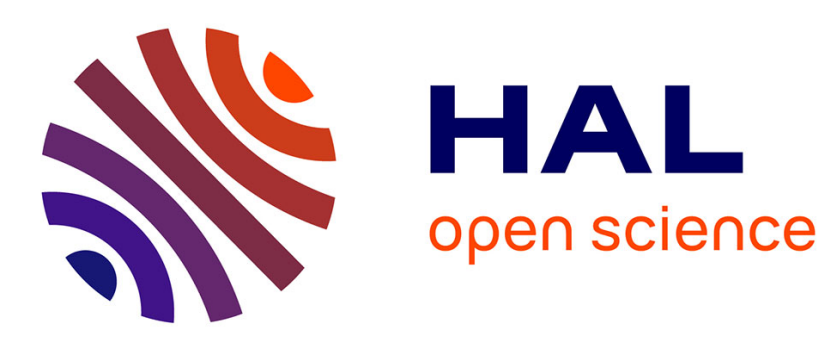

\title{
The Failure Mechanisms of Micro-scale Cantilevers in Shock And Vibration Stimuli
}

\author{
M. Sheehy, M. Reid, J. Punch, S. Goyal, G. Kelly
}

\section{To cite this version:}

M. Sheehy, M. Reid, J. Punch, S. Goyal, G. Kelly. The Failure Mechanisms of Micro-scale Cantilevers in Shock And Vibration Stimuli. DTIP 2008, Apr 2008, Nice, France. pp.2-7. hal-00277668

\section{HAL Id: hal-00277668 \\ https://hal.science/hal-00277668}

Submitted on 7 May 2008

HAL is a multi-disciplinary open access archive for the deposit and dissemination of scientific research documents, whether they are published or not. The documents may come from teaching and research institutions in France or abroad, or from public or private research centers.
L'archive ouverte pluridisciplinaire HAL, est destinée au dépôt et à la diffusion de documents scientifiques de niveau recherche, publiés ou non, émanant des établissements d'enseignement et de recherche français ou étrangers, des laboratoires publics ou privés. 


\title{
The Failure Mechanisms of Micro-scale Cantilevers in Shock and Vibration Stimuli
}

\author{
Michael Sheehy ${ }^{1}$, Michael Reid ${ }^{1}$, Jeff Punch ${ }^{1}$, Suresh Goyal ${ }^{2}$, Gerard Kelly ${ }^{1}$ \\ ${ }^{1}$ CTVR/Stokes Institute, Engineering Research Building, University of Limerick, Limerick, Ireland. \\ ${ }^{2}$ Bell Labs Ireland, Lucent Technologies, Blanchardstown Industrial Park, Blanchardstown, Dublin 15, Ireland.
}

\begin{abstract}
Contemporary shock testing of micro-devices is carried out in controlled test environments where test parameters can be monitored with current metrology techniques. Due to demanding environments and limited scope of design rules, the reliability of micro devices has become a concern. A modified Hopkinson pressure bar (HPB) is used to investigate failure mechanisms of single crystal silicon (SCS) microcantilever devices under high-g accelerations. Response upon impact is monitored using high speed imaging (HSI) to ascertain the cause of failure. White light interferometry (WLI) and scanning electron microscopy (SEM) are used as post analysis techniques to investigate cause of failure and fracture topography. The modified HPB method in conjunction with high speed imaging allowed valid prediction of modal and temporal failure information of the micro cantilevers. WLI investigated the effects of deep reactive ion etching (DRIE) etching on crack instigation. SEM identified octahedral cleavage of SCS as the dominant failure mechanism of the micro-cantilevers.
\end{abstract}

\section{INTRODUCTION}

The reliability of microelectromechanical systems (MEMS) has become an increasing concern with the current development and applications of micro-scale devices in fields such as military and aerospace. Devices which were once considered indestructible to a transient mechanical event are now being employed in harsh environments which generate stresses that can induce failure [1].

Key developments in MEMS fatigue and fracture research have been carried out through methods varying from resonance excitation, static deflection loading and design specific on-chip approaches to implement techniques such as electrostatic actuation [2-6]. Test procedures and metrology techniques have been simultaneously developed and these approaches have contributed to the characterisation of material and geometry properties of micro-devices. When establishing a new test method, silicon is the fabrication material of choice due to its inherent use in MEMS fabrication and also due to the brittle nature of single crystal silicon (SCS) and polycrystalline silicon [7]. Once a test method is developed with established materials and geometries, it is then applied to a broader range of materials for application specific designs. Reference [8] investigates several approaches in literature with respect to fatigue and fracture testing of silicon devices. Fabrication processes are proven to have an effect on the fracture strength of a device whereby wet etching techniques yield lower silicon strengths than reactive ion etching (RIE) techniques and crystal orientation is also known to influence silicon strength within RIE techniques. Further investigation also shows that different test methods on an identical fabrication process yield variations in Young's modulus and fracture strengths. References [5] and [6] investigate the effects of fatigue through cyclic loading and show that SCS fails at lower strains than its static failure strain. Fracture sites are observed through scanning electron microscopy (SEM) and confirm that variations in strain amplitude under cyclic loading affect the crack propagation and failure mode as in [6]. Reference [9] conducted a comprehensive review on the mirror, mist and hackle fractography of single crystals at several scales to provide a tool for the study of brittle cleavage fracture in single crystals.

However, even with advances such as these to characterise material response at a micro-scale, the majority of mechanical testing that has been carried out in current literature is carried out in static environments where excitation of a given device is relatively deterministic. This trend has partly been due to the limitations of instrumentation and existing techniques but predominantly to enable predictable boundary conditions in static environments which enable higher accuracy when correlating results theoretically [7].

With the growing number of commercial applications for MEMS, research at micro-scale has shifted from passive device characterisation to active device reliability, as seen with the development of the Texas Instruments Digital Micromirror Device [10]. The need for reliability characterisation of devices coupled with harsher application environments has led to a requirement for highly transient dynamic testing of micro-scale devices. There are a select number of methods of producing high amplitude repeatable shock pulses that are capable of exciting micro-scale devices to failure; such as drop tables, ballistics, Hopkinson pressure bars (HPBs) and explosives [11-15]. Due to the complexity of the test environments for these methods, there are also only a limited range of measurement techniques to realise any quantitative information from a test program. Therefore when creating a 
reliability test program, it is necessary to develop measurement techniques that are capable of monitoring the in-situ response of a micro-scale device as well as post analyses techniques to ascertain modes of failure.

This paper will investigate the effectiveness of high strain rate shock tests on SCS micro-cantilevers as a test method for characterising fatigue and crack growth in MEMS materials. It will also correlate the transition from low to high strain rate testing and serve as a supplement to current design rules in predicting the failure modes of devices employed in shock environments.

\section{FABRICATION PROCESS}

Bulk SCS micro-cantilevers were fabricated from $100 \mathrm{~mm}$ p-type $<100>$ SCS wafer of $525 \mu$ m thickness with a primary flat orientation of [110]. The beams had characteristic lengths of $1-7 \mathrm{~mm}$ with cross sections $100 \mu \mathrm{m} \times 50 \mu \mathrm{m}, 100 \mu \mathrm{m} \times$ $100 \mu \mathrm{m}$ and $100 \mu \mathrm{m} \times 200 \mu \mathrm{m}$. Several of the beams also had proofmasses at the beam tips to influence their response under deflection. Finally each beam type was reproduced with notches of $10 \%$ and $40 \%$ of beam width to induce failure and/or degradation in the material through stress raisers. Fig. 1 shows a front-side image of a SCS micro-cantilever sample within a frame for mounting on the test apparatus. The sample shown has a $5 \mathrm{~mm}, 6 \mathrm{~mm}$ and $7 \mathrm{~mm}$ beams with proofmasses at the beam tips.

The fabrication process was carried out in 54 run steps consisting of cleaning, inspection and physical steps. A thin film oxide layer was deposited onto the front-side and backside of the wafer and the front-side mask was used to transfer the beam geometry onto the oxide surface by means of photolithography. The patterned oxide layer was then stripped off using RIE and the remaining photoresist was stripped from the front-side. A nitride layer was then deposited both front and back-side by means of low pressure chemical vapour deposition (LPCVD) to act as a barrier for a following potassium hydroxide $(\mathrm{KOH})$ solution wet etch. The back-side mask was then used to pattern photoresist onto the wafer and the oxide/nitride layers were removed using a RIE etch.

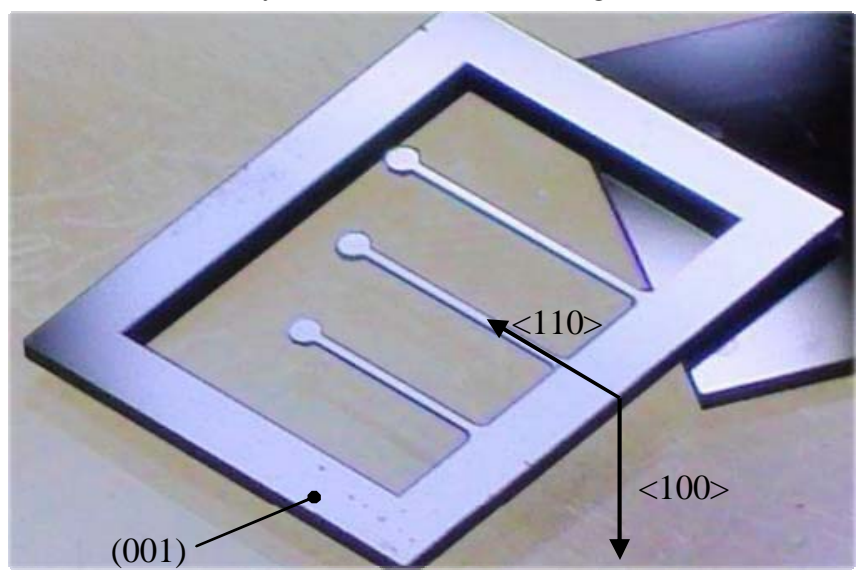

Fig. 1. SEM Image of SCS micro-cantilever structure displaying the relative lattice planes and directions.
The remaining photoresist was stripped and a timed anisotropic $\mathrm{KOH}$ etch was used to remove $425 \mu \mathrm{m}$ of the SCS to obtain the $100 \mu \mathrm{m}$ beam depth. The nitride layer was then removed and aluminium and polyimide layers were deposited on the back-side to act as an etch stop and support the micro-cantilevers while under vacuum respectively. Deep RIE (DRIE) was then used to etch out the beam geometries on the front-side of the wafer. All sacrificial layers were then stripped from the wafer before dicing and cleaning to finish the fabrication process. Table 1 summarises the fabrication procedure into the main physical run steps and Fig. 2 shows a wafer cross section during the process steps.

TABLE 1

FABRICATION PROCESS RUN STEPS

\begin{tabular}{|c|c|c|}
\hline No & Step & Description \\
\hline & \multicolumn{2}{|c|}{ Wafer: $100 \mathrm{~mm}$ dia. $-525 \mu \mathrm{m}$ thick - P-type $<100>$ SCS } \\
\hline 1 & Variable wet oxide & $1 \mu \mathrm{m}$ thick \\
\hline 2 & Photolithography & $\begin{array}{l}8.7 \mu \mathrm{m} \text { photoresist coat } \text { - front-side mask } \\
\text { exposure }\end{array}$ \\
\hline 3 & Shallow oxide etch & $\begin{array}{l}\text { Remove oxide to form front-side beam } \\
\text { pattern for DRIE }\end{array}$ \\
\hline 4 & Photoresist Strip & - \\
\hline 5 & LPCVD & $\begin{array}{l}\text { Deposit nitride layer for } \\
\text { front-side/back-side } \mathrm{KOH} \text { protection }\end{array}$ \\
\hline 6 & Photolithography & $\begin{array}{l}8.7 \mu \mathrm{m} \text { photoresist coat - back-side mask } \\
\text { exposure }\end{array}$ \\
\hline 7 & $\begin{array}{l}\text { Shallow oxide/nitride } \\
\text { etch }\end{array}$ & $\begin{array}{l}\text { Remove oxide/nitride to form back-side } \\
\text { beam release geometry }\end{array}$ \\
\hline 8 & Photoresist Strip & - \\
\hline 9 & $\mathrm{KOH}$ etch & $\begin{array}{l}\text { back-side } \mathrm{KOH} \text { wet etch }-425 \mu \mathrm{m} \text { depth } \\
\text { to define } 100 \mu \mathrm{m} \text { beam depth }\end{array}$ \\
\hline 10 & Nitride removal & - \\
\hline 11 & Aluminium sputter & $\begin{array}{l}6 \mu \mathrm{m} \text { Al. sputter on back-side to act as } \\
\text { etch stop in DRIE etch }\end{array}$ \\
\hline 12 & $\begin{array}{l}\text { Polyimide support } \\
\text { layer }\end{array}$ & $\begin{array}{l}\text { Polyimide coat on back-side to support } \\
\text { beams under vacuum in DRIE etch }\end{array}$ \\
\hline 13 & DRIE etch & $\begin{array}{l}\text { Front-side etch of beam geometry using } \\
\text { oxide mask }-100 \mu \mathrm{m} \text { depth }-6-10 \mu \mathrm{m} / \mathrm{min}\end{array}$ \\
\hline 14 & Finishing & $\begin{array}{l}\text { Removal of sacrificial layers - } \\
\text { Al./nitride/oxide - cleaning }\end{array}$ \\
\hline
\end{tabular}

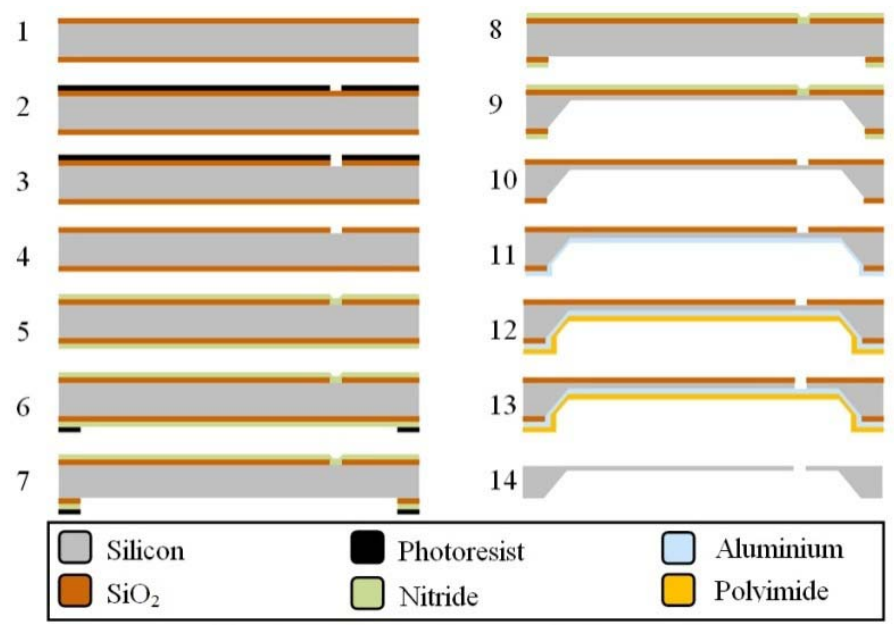

Fig. 2. Fabrication process of micro-cantilevers. 


\section{DTIP}

From reference [8] it has been proven that the choice of fabrication process influences the strength of device under test. A WYKO NT3300 was used to measure the DRIE and $\mathrm{KOH}$ etch profiles by means of white light interferometry (WLI). Measurement was carried out in Phase Shift Interferometry (PSI) mode yielding up to $1 \mathrm{~nm}$ resolution accuracy in the z-axis. Fig. 3 shows interferograms of representative etch profiles on the micro-cantilever beam surfaces where the depth in the images is increased in scale to enhance the profile. Fig. 3(a) shows a depth profile of a $\mathrm{KOH}$ etched surface of the proofmass of a micro-cantilever beam. Due to the timed etch stop in the $\mathrm{KOH}$ etch there will be variations in depth across the (001) plane etch surface. The surface roughness, $\mathrm{R}_{\mathrm{a}}$, of the $\mathrm{KOH}$ etch is in the region of 20nm. In Fig. 3(b) the typical scalloping and footing effects

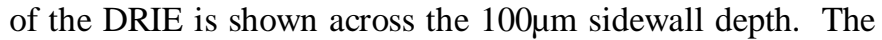
scalloping caused by the passivation/etching cycle resulted in a corrugation of approximately 90-95 steps for the $100 \mu \mathrm{m}$ depth. The footing effect of the etch results in andulating negative curve of approximately $500 \mathrm{~nm}$ in the sidewall. The WLI results indicate that the surface roughnesses of the $\mathrm{KOH}$ and DRIE etches are insignificant relative to the overall scale of the cantilevers. It is not likely that surface profile will influence the strength of the beams, however the corrugated profile of the DRIE etch may develop failure instigation loci.
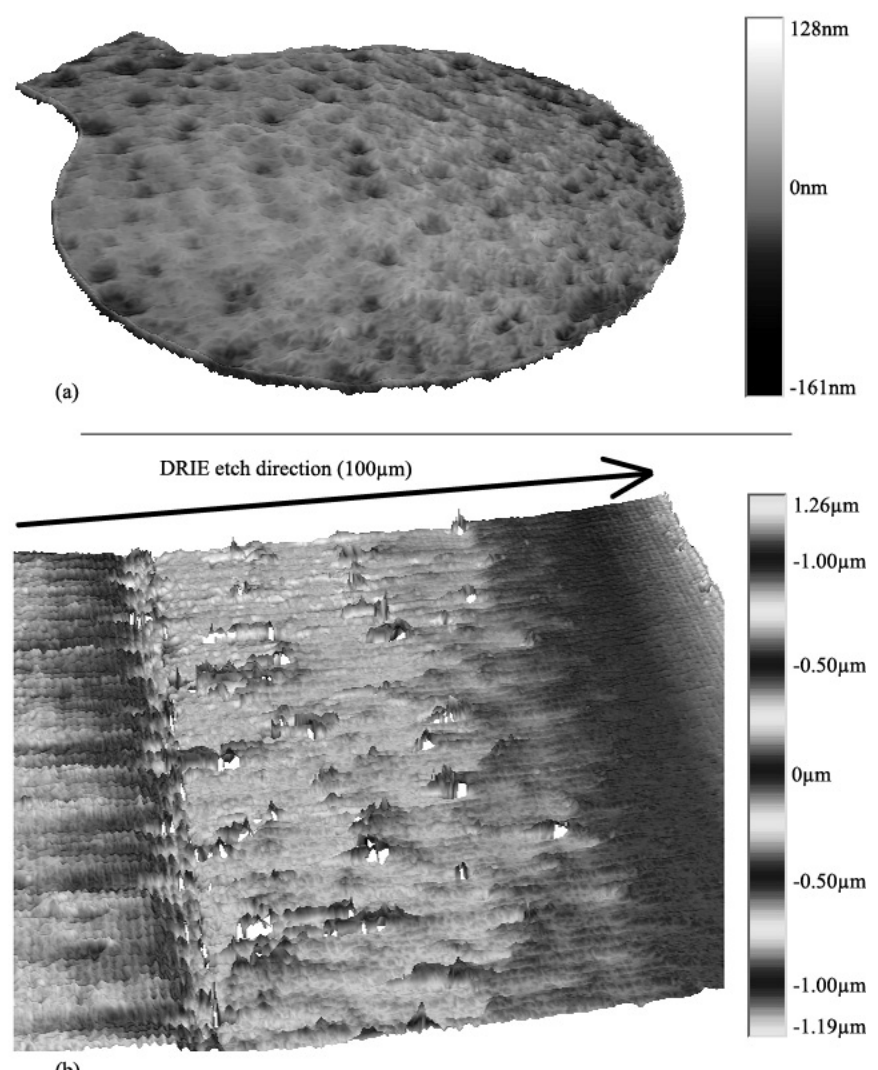

(b)

Fig. 3 Interferograms of (a) KOH etch of back-side of proofmass (b) DRIE etch profile of beam sidewall.
EXPERIMENTAL PROCEDURE

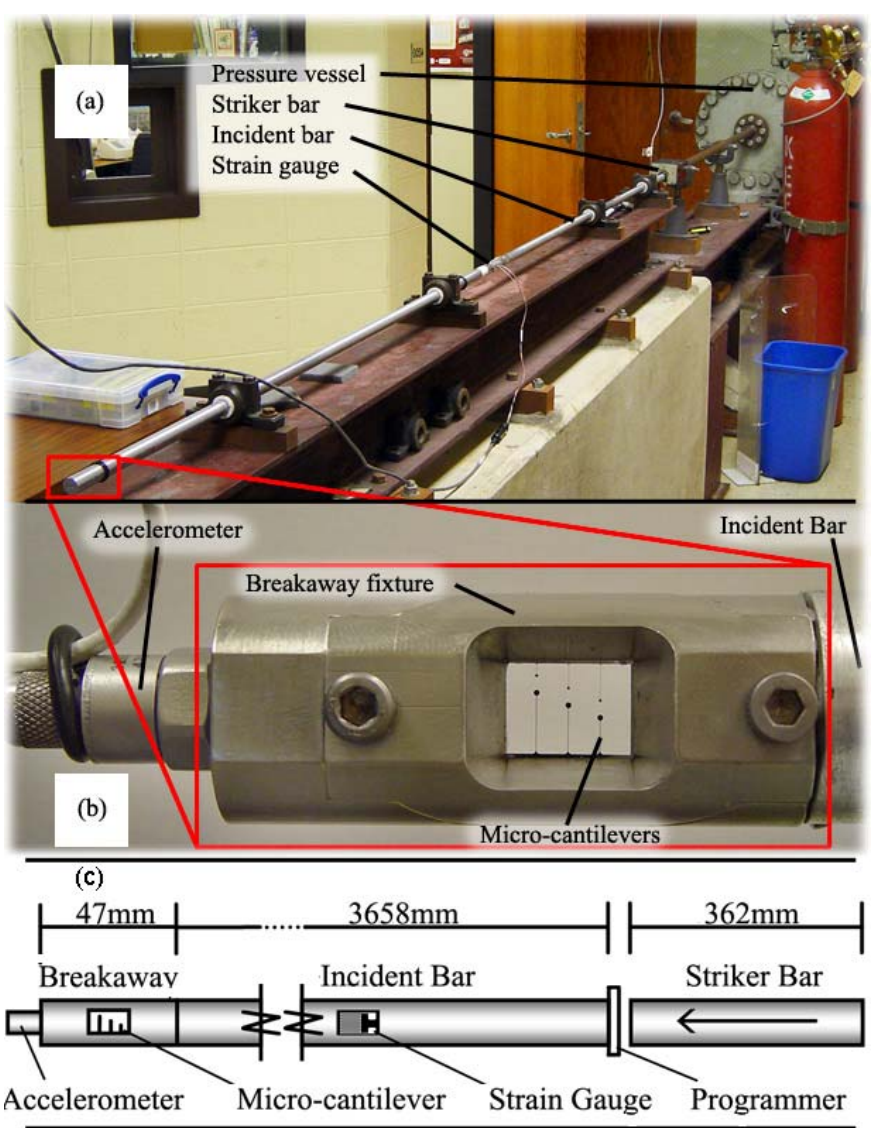

Fig. 4. (a) HPB apparatus (b) breakaway fixture with micro-cantilever frame and accelerometer (c) schematic diagram of experimental setup.

The micro-cantilevers were mounted in a breakaway fixture on a modified Hopkinson pressure bar, as in Fig. 4. The HPB was made of an aluminium 6061-T651 incident rod of $19 \mathrm{~mm}$ diameter and $3.658 \mathrm{~m}$ length with strain gauges midsection. This rod was struck at one end by an aluminium striker bar of $19 \mathrm{~mm}$ diameter and $362 \mathrm{~mm}$ length. A pressurised gas chamber propels the striker bar into one end of the incident bar. At this impact point $2.8 \mathrm{~mm}$ to $4.4 \mathrm{~mm}$ thick stationary card was used as a programming material to shape the pulse wave. This generated the desired compression wave that travelled through the incident bar ultimately delivering a shock pulse to the breakaway fixture. The stainless steel breakaway fixture was bonded to the HPB such that it separated from the incident bar after the initial shock to avoid any additional excitation impulses. The opposing end was threaded for attachment of a Dytran 3200B 80,000g accelerometer. The strain gauge signal was amplified through a Vishay 2110 strain gage conditioner and acquired by a FLUKE PM3394A oscilloscope at 2.5MHz. The accelerometer signal was conditioned through a National Instruments (NI) SC-2345 and acquired by an NI-USB-6251 at $1.25 \mathrm{MHz}$. An IDT MotionPro ${ }^{\mathrm{TM}} \mathrm{X}$ high speed camera with 
a Computar TEC-55 telecentric lens monitored the impact event on the cantilevers to verify the temporal point of failure.

\section{RESULTS AND DISCUSSION}

Acceleration levels between $10,000 \mathrm{~g}$ and $40,000 \mathrm{~g}$ were required to induce failure mechanisms in the microcantilevers depending on the beam characteristics. This was achieved by launching the striker bar at a velocity of approximately $11-24 \mathrm{~m} / \mathrm{s}$. In order of significance; proofmass, cross section dimensions, notch size and beam length determined the shock level required to induce failure in the beams. Fig. 5 shows characteristic acceleration amplitudes and durations from the strain gauge and accelerometer signals over the 10,000-40,000g input range.

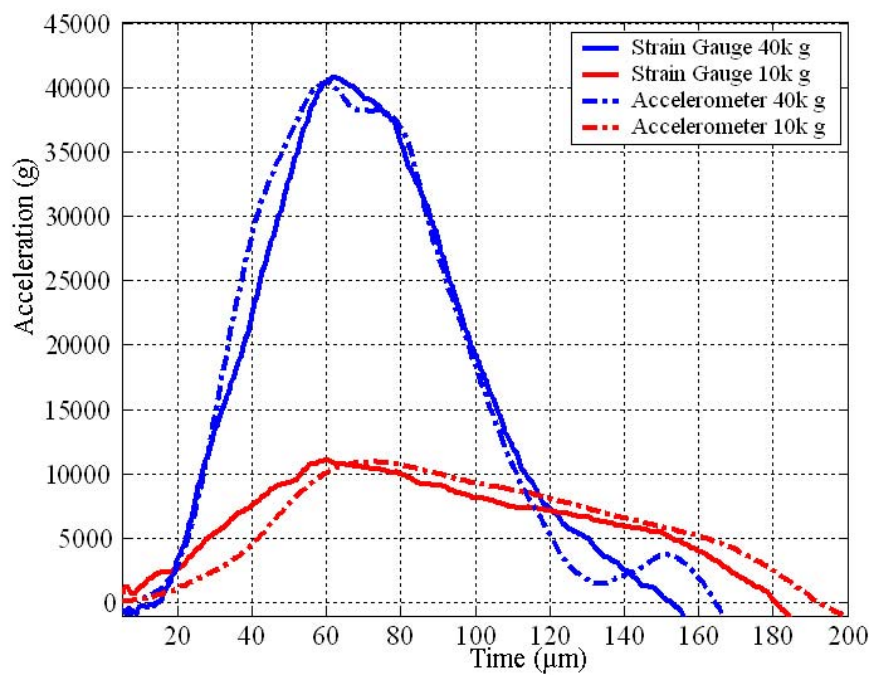

Fig. 5. Characteristic shock acceleration pulses taken from accelerometer and strain gauge signals.

Several failure modes were found upon inspection of the micro-cantilevers across all acceleration amplitudes. The high speed imaging (HIS) provided information on the cause of failure and determined if it was a result of the initial shock pulse or other phenomena such as fatigue failure after several oscillations and collision between beams. HSI also highlighted out of plane vibration of the beams in relation to the primary shock direction which can be caused by irregularities such as buckling of the beams under high strain or misalignments upon impact. Although, this may also be attributed to excitation of out of plane resonant frequencies as high frequency transients are unavoidable when inducing high amplitude low duration shocks.

Fig. 6 is a schematic of a frame with $5 \mathrm{~mm}, 6 \mathrm{~mm}$ and $7 \mathrm{~mm}$ beams of $100 \mu \mathrm{m} \times 200 \mu \mathrm{m}$ cross section and $40 \%$ notch. Shock direction and notch geometry are highlighted, and a high speed image of the shock event shows the failure loci to be at the base of the $6 \mathrm{~mm}$ and $7 \mathrm{~mm}$ beams in the region of the notch. In this image, the primary mode of failure for the shock excitation of the beams is shown. Depending on the

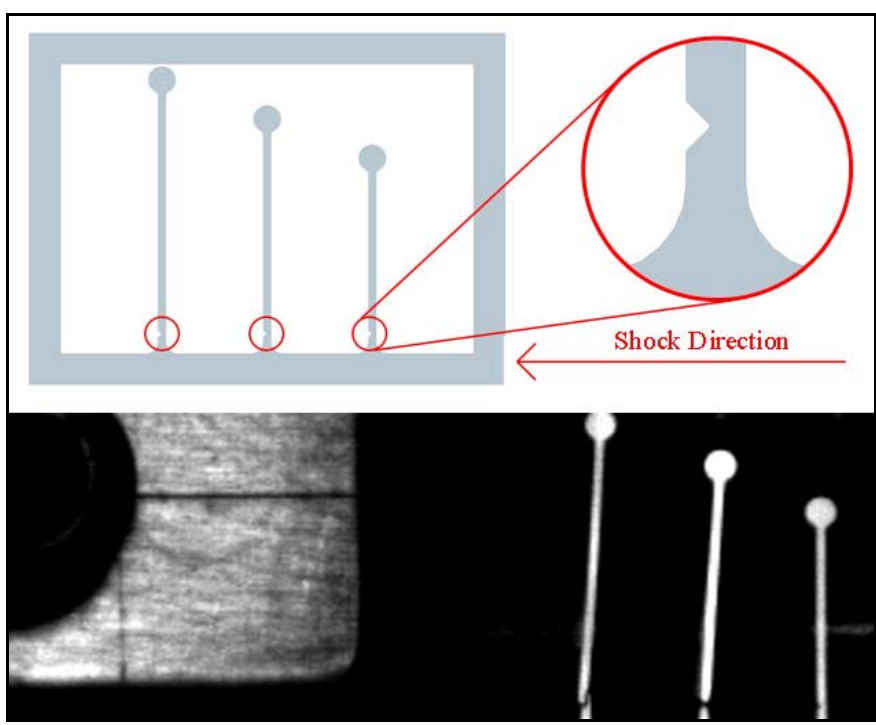

Fig. 6 (a) Beam schematic highlighting notch geometry and shock direction and (b) high speed image of test specimen at point of failure.

acceleration level, failure occurs approximately $150 \mu \mathrm{s}$ after the shock is induced at the base of the beam.

A JEOL JSM-840 scanning electron microscope (SEM) was used to obtain low and high magnification electron images of fracture surface using secondary electrons at $20 \mathrm{kV}$. It was observed under SEM that, with or without a notch, failure occurred at the beam base as predetermined by ANSYS simulations of maximum stress location. In the presence of a notch, the region of smallest cross-sectionalarea acted as a stress raiser to instigate failure. However, it was found that even though the notch root yielded the highest stresses, once failure mechanisms initiated, the failure path followed the octahedral cleavage planes of the single crystal silicon i.e. the $\{111\}$ planes.

The images depicted in Fig. 7(a-b) show secondary electron images of the fracture/cleavage surfaces for $6 \mathrm{~mm}$ and $7 \mathrm{~mm}$ beams respectively. These images both show three distinct surfaces; the notch surface can be seen in the right of the image (also clarified in Fig. 6), the first fracture surface showing the $\{111\}$ cleavage planes can be seen in the centre of the images and the second fracture surface can be seen in the left of the images. These images show beams which have failed immediately under a $10,000 \mathrm{~g}$ acceleration shock. The WLI of the etch profiles highlight that failure mechanisms are initiated at surface flaws from fabrication processes. The fracture origin is not seen in detail but lies along the edge of two faceted $\{111\}$ cleavage surfaces in the region of the notch root caused by tension of the beam under flexure. With regard to the primary failure mode, Fig. 8 is a higher magnification of the lower (111) cleavage surface of the $7 \mathrm{~mm}$ beam highlighted in Fig. 7(b). Yet again here the octahedral cleavage face is well defined, and in the mid to lower right hand side of the image, striations highlight that even under the influence of the [001] direction notch root the cleavage planes still recede to a common (111) slip plane. 


\section{DTIP}

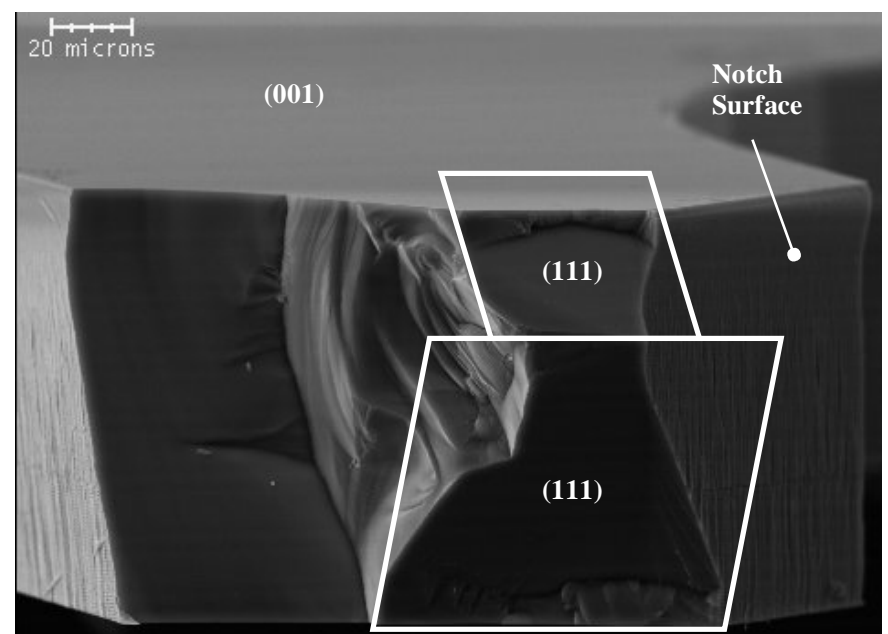

(a)

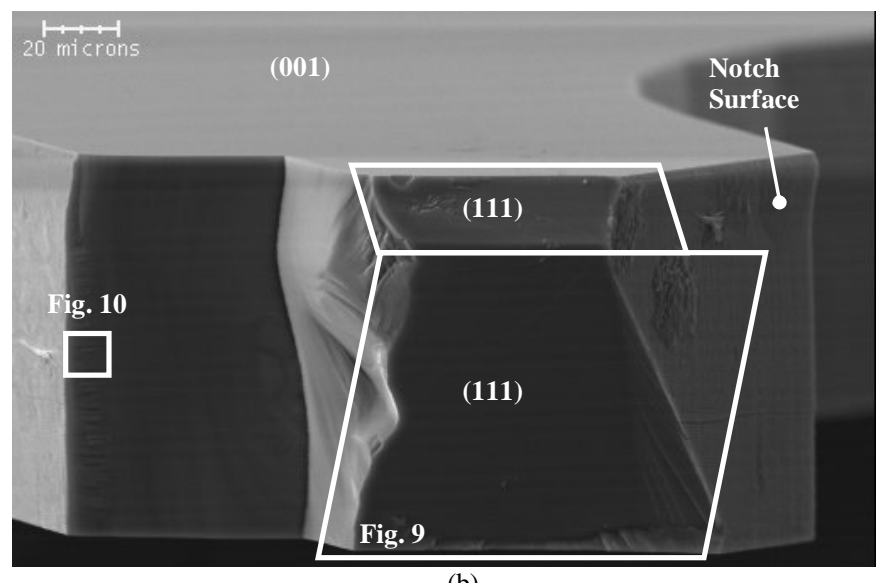

(b)

Fig. 7 Fracture surfaces of (a) $6 \mathrm{~mm}$ beam and (b) $7 \mathrm{~mm}$ beam.

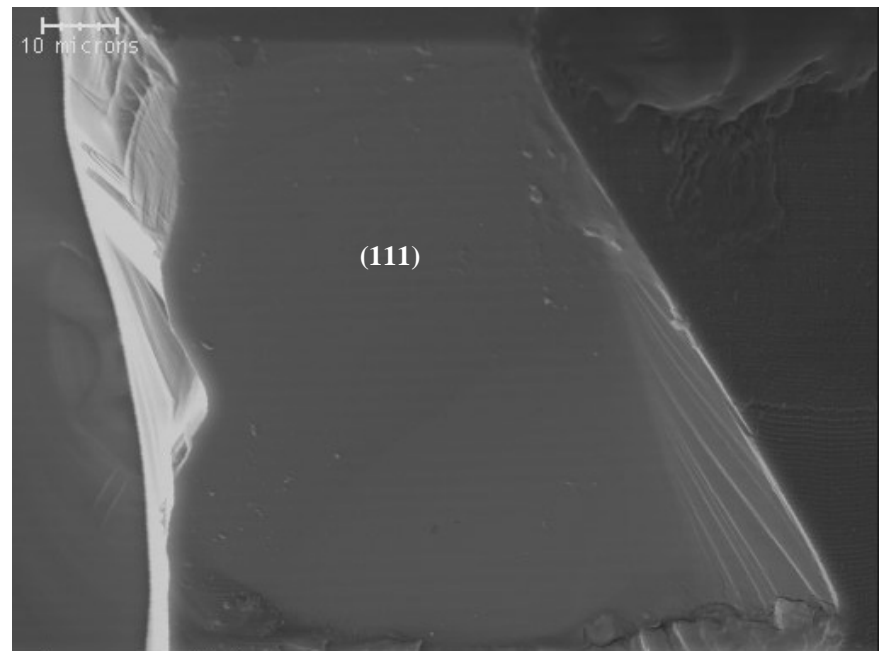

Fig. 8 Lower (111) plane fracture surface on $7 \mathrm{~mm}$ beam.
It was also seen that in the absence of a notch, cleavage remained on a single (111) plane and was not redirected onto a second (111) plane (as seen in Fig. 7). This indicates that the presence of a notch influenced cleavage planes to redirect.

Thus failure instigation occurred at the intersection of (001) and (111) planes in the region of maximum stress from beam flexure and/or near surface flaws from fabrication processes. The absence of mist and hackle in these surfaces indicates that the fracture did not reach terminal velocity along the middle part of the spreading fracture front. This was further attributed to the fracture moving into a region of lower tension.

With regard to the second fracture surface observed, and in agreement with [9], a brittle cleavage fracture surface normal to the tensile axis can be seen here with the presence of mirror, mist and hackle, as in Fig. 9. Here, fracture nucleates from the right and propagates to the left with the SEM image showing transition of the three stages. In this sample the mirror region dominates the fracture surface with the mist and hackle observed near the trailing edge covering approximately $2 \mu \mathrm{m}$ and $6 \mu \mathrm{m}$ respectively. From this it is evident that the crack tip had a much higher propagation velocity as it approached the edge of the beam in comparison with the first fracture surface. This higher velocity produces greater micro-mechanical activity at the crack tip where the increase in both stress intensity and rate of energy release results in the mist and hackle appearance.

The findings in this paper and their correlation with current literature prove the viability of both HPB as a test method and HSI as a metrology technique for testing micro-devices under high-g shock.

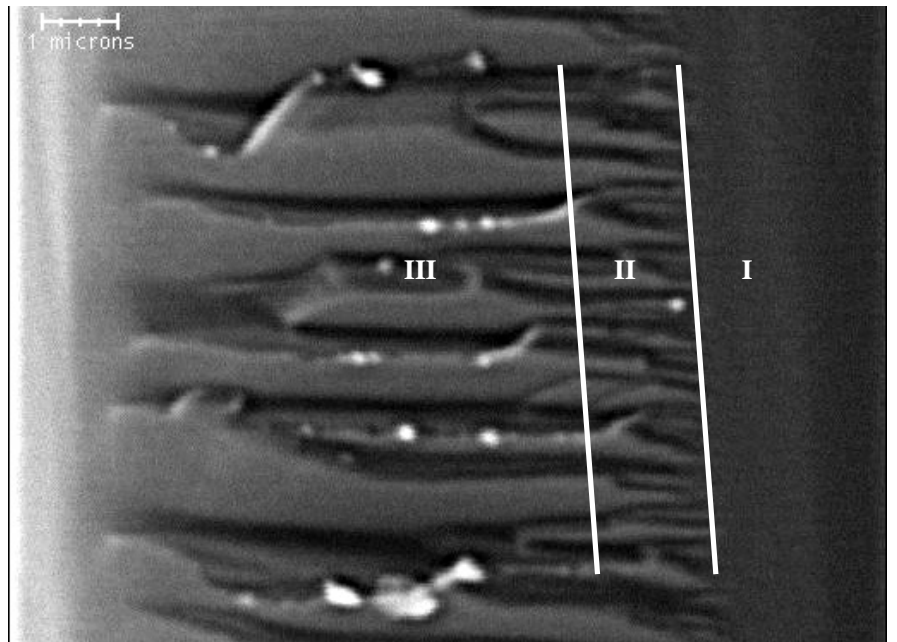

Fig. 9 SEM image of the trailing edge of fracture surface indicating the (I) mirror, (II) mist and (III) hackle region. 


\section{CONCLUSIONS}

Due to the non-deterministic nature of shock environments, the use of HSI is an essential technique in determining the insitu modal and temporal information of failure mechanisms. It allows an informative assessment of the cause of failure. While several failure modes occurred during the experimentation, these were all observed in the HSI which allowed selection of dominant modes for further observation.

Initial cleavage facets occurred predominantly on the \{111\} planes and immediate high acceleration failures highlighted rougher surface topography whereas lower acceleration fatigued failures yielded more consistent mirrored topography. The secondary fracture surfaces indicated higher velocity fractures due to the presence of mirror, mist and hackle topography and fracture surface normal to tensile axis.

WLI of the etch profiles in conjunction with a study of the dominant fracture surfaces of SCS shows that while surface flaws produced from fabrication processes initiate failure mechanisms, crystal orientation plays a primary role in crack propagation direction.

\section{ACKNOWLEDGEMENT}

The author would like to acknowledge the Tyndall Institute in Cork, Ireland for the fabrication of the micro-cantilevers under the National Access Programme (NAP).

The author would like to acknowledge Prof. Rick Hall, University of Delaware for his helpful support and the use of the HPB test equipment.

The author would like to acknowledge the IRCSET (Irish Research Council for Science, Engineering and Technology) for their support of this work. The work is also supported by Science Foundation Ireland under grant number 03/CE3/I405.

\section{REFERENCES}

[1] V.T. Srikar, D. Senturia, "The Reliability of Microelectromechanical Systems (MEMS) in Shock Environments," J. Microelectromech. Syst., vol. 11, pp. 206-214, 2002.

[2] O.B. Ozdoganlar, B.D. Hansche, T.G. Carne, "Experimental modal analysis for microelectromechanical systems," J. of Experimental Mechanics, Vol. 45, pp. 498-506, 2003.

[3] D.S. Epp, O.B. Ozdoganlar, P.M. Chaplya, B.D. Hansche, T.G. Carne, "A Base Excitation Test Facility for Dynamic Testing of Microsystems," Proc. of $22^{\text {nd }}$ Int. Modal Analysis Conf. (IMAC), 2004.

[4] O.N. Pierron, C.L. Muhlstein, "Notch Root Oxide Formation During Fatigue of Polycrystalline Silicon Structural Films," J. of MEMS, Vol. 16, pp. 1441-1450, 2007.
[5] C.L. Muhlstein, S.B. Brown, R.O. Ritchie, "High-cycle fatigue of single-crystal silicon thin films," J. of MEMS, Vol. 10. pp. 593-600, 2001.

[6] H.K. Liu, B.J. Lee, P-P. Liu, "Low cycle fatigue of single crystal silicon thin films," J. of Sensors and Actuators A: Physical, Vol. 140, pp. 257-265, 2007.

[7] M. Gad-El-Hak, "The MEMS Handbook", CRC Press: New York, 2002.

[8] T. Yi and C. J. Kim, "Measurement of mechanical properties for MEMS materials," J. of Meas. Sci. Technol., Vol. 10, pp. 706-716, 1999.

[9] D. Hull, "Fractography: Observing, Measuring and Interpreting Fracture Surface Topography" Cambridge University Press: UK, 1999.

[10] M.R. Douglass, "Lifetime Estimates and Unique Failure Mechanisms of the Digital Micromirror Device," IEEE Int. Reliability Physics Symp., pp. 9-16, 1998.

[11]T.G. Brown, "Harsh Military Environments and Microelectromechanical (MEMS) Devices," Proceedings of IEEE Sensors, Vol. 2, pp. 753-760, 2003.

[12] G.X. Li, F.A. Shemansky, "Drop test and analysis on micro-machined structures," J. of Sensors and Actuators A: Physical, Vol. 85, pp. 280-286, 2000.

[13]D.M. Tanner, et al, "MEMS reliability in shock environments," Proc. of IEEE Int. Reliability Physics Symp., pp. 129-138, 2000.

[14] W.Y. Lu, H. Jin, S. Lee, K. Gwinn, W. Chen, B. Song, "Dynamic loading of LIGA structures," Proc. of SEM Conf. and Expo. on Exp. and Applied Mechanics, Vol. 3, pp. 1232-1239, 2006.

[15]G. Kelly, M. Sheehy, B. Rodgers, J. Punch, S. Goyal, "Analysis of high acceleration shock pulses part I: Geometry of Incident Mass", Proc. of SEM Conf. and Expo. on Exp. and Applied Mechanics, 2007. 